\title{
A prática docente e os vestibulares: diálogos (im)possíveis
}

\author{
Ester Machna de Mendonça \\ Universidade Federal do Paraná (UFPR), Curitiba, Paraná, Brasil \\ estermachna@gmail.com
}

DOI: http://dx.doi.org/10.21165/el.v46i2.1581

\begin{abstract}
Resumo
O presente artigo tem por objetivo discutir os impactos que os vestibulares (incluindo o Exame Nacional do Ensino Médio) provocam nas práticas docentes cotidianas de professores de Língua Portuguesa do Ensino Médio da região de Curitiba. A partir das respostas dadas em um questionário online, aplicado no final do primeiro semestre de 2016, somada à observação de aulas e análise de materiais utilizados, foi possível perceber que, nessa etapa de ensino, o impacto exercido por esses exames é significativo e, em muitos casos, determinante em relação aos conteúdos abordados em sala de aula. Diante disso, é preciso que a formação desses profissionais considere tais interferências, tanto para problematizá-las quanto para instrumentalizar o professor, em constante embate entre as diversas vozes que marcam a prática docente.
\end{abstract}

Palavras-chave: políticas linguísticas; efeito retroativo; vestibular; prática docente.

\section{Teaching practices and entrance examinations: (im) possible dialogues}

\begin{abstract}
This article aims to discuss the impacts of the entrance exams (including the Exame Nacional do Ensino Médio [Brazilian College Entrance Exam]) on teaching practices of Portuguese language teachers in high school of Curitiba region. From the answers given in an online questionnaire applied at the end of the first half of 2016, as well as lessons observations and material analysis, it was revealed that the impact played by these tests is significant at this level of teaching. Also, in many cases, it is decisive regarding contents covered in classroom. Therefore, it is necessary for the formation of these professionals to consider such interferences, both to discuss them as to provide tools for the teacher in constant conflict between the diverse voices that characterize the teaching practice.
\end{abstract}

Keywords: language policies; washback effect; entrance exam; teaching practice.

\section{Introdução}

A prática docente é marcada por uma série de vozes (BAKHTIN, 2015) e de discursos que se entrecruzam, alguns dos quais competem entre si. Os saberes dos professores são múltiplos e provenientes de diversas fontes, estas irreconhecíveis à primeira vista, na observação de seu trabalho (TARDIF, 2014). No caso dos professores de Língua Portuguesa, há, de um lado, a voz da tradição gramatical, impregnada na história escolar da maioria dos futuros docentes, e, de outro, a dos estudos da linguagem, determinada a romper as concepções tradicionais de língua e ensino.

Contudo, na prática profissional, o professor também se encontra constantemente com outra voz: a do vestibular, que oscila, em vários momentos, entre concepções mais ou menos tradicionais e atuais em relação à linguagem. Em muitos espaços escolares, especialmente os privados, a despeito das normatizações e orientações curriculares propostas pelos PCN e OCEM, os exames impactam currículos e lançam diretrizes para 
a prática do professor - o efeito retroativo (QUEVEDO-CAMARGO, 2014). Nesse contexto, o objetivo deste artigo é discutir como esse impacto (seja este positivo ou negativo) exercido pelos vestibulares (incluindo o Exame Nacional do Ensino Médio) se dá na prática profissional dos professores de escolas públicas e particulares da região de Curitiba.

A discussão aqui proposta tem como base um questionário online respondido por professores e professoras de Língua Portuguesa que atuam ou tenham atuado recentemente no Ensino Médio, sobre o impacto dos testes no cotidiano docente ${ }^{1}$. Composto por 16 questões abertas e fechadas, incluindo perguntas sobre o perfil do entrevistado (tempo de formação, local de atuação, entre outras), o questionário foi disponibilizado para respostas durante um mês. Foram 12 respondentes, entre recémformados e formados há mais tempo, que atuam em escolas públicas $(41,67 \%)$, privadas $(50 \%)$, em ambas $(8,33 \%)$ ou são autônomos $(8,33 \%)$. Após coletadas, as respostas foram interpretadas tendo em vista os trabalhos de Shohamy $(1993 ; 2006)$, a respeito dos impactos dos testes no cotidiano escolar e na prática docente. Além disso, as aulas de alguns professores e os materiais por eles utilizados também foram analisados, a fim de verificar se as respostas dos questionários coincidiam com as práticas de facto.

Os resultados mostram que os impactos, apesar de diversos, são significativos na rotina desses profissionais, especialmente em relação à escolha dos conteúdos abordados e aos materiais utilizados. O contexto de atuação também contribui para diferentes impactos: enquanto nas escolas particulares há exigências institucionais para que os exames respaldem o ensino, não houve relatos da mesma natureza nas escolas públicas. A maior parte dos participantes, contudo, contrariando as expectativas comuns na literatura, considera que esses exames contribuem para a sua formação, ou seja, encara como positivo o impacto dos exames em seu cotidiano profissional. Assim, levando em consideração as constatações dos professores, o efeito retroativo desses exames na prática docente, mesmo que seja limitador em muitos momentos, pode fornecer subsídios para uma formação profissional mais atenta às demandas reais dos docentes em seus âmbitos de atuação.

\section{Fundamentação teórica}

A fim de balizar a discussão aqui proposta, é importante situar o lugar em que o presente artigo se coloca. Entendemos que os vestibulares, assim como outros exames de alta relevância, tanto para alunos quanto para professores, são mecanismos de políticas linguísticas (SHOHAMY, 1993; 2006), os quais ajudam a criar e a perpetuar determinadas concepções em relação à língua e, consequentemente, aos seus falantes. Contudo, antes de abordarmos essa perspectiva, é preciso reconstituir brevemente o caminho percorrido pelos estudos do campo, até chegarmos ao entendimento de políticas linguísticas aqui proposto. Portanto, primeiramente, faremos uma breve retomada das pesquisas desenvolvidas na área, com o objetivo de contextualizar o lugar teórico desta pesquisa. A seguir, apresentaremos a concepção ampliada de política linguística, proposta por Spolsky (2004) e posteriormente desenvolvida por Shohamy (2006). Por fim, serão tecidas algumas considerações sobre o efeito retroativo, fenômeno relevante para as análises aqui propostas.

\footnotetext{
${ }^{1} \mathrm{O}$ questionário completo está anexo a este artigo.
} 


\section{Políticas linguísticas: breve percurso}

As pesquisas no campo das políticas linguísticas, em seu estágio inicial denominado por Ricento (2000) de descolonização, estruturalismo e pragmatismo foram marcadas pela crença de que os problemas linguísticos de uma determinada comunidade poderiam ser resolvidos por meio do planejamento linguístico, ou seja, pela construção de dicionários e de gramáticas, por padronizações e modernizações na língua, bem como pela determinação dos usos que cada língua deveria ter em um determinado contexto social. Nesse período, entendia-se por problema uma comunidade multilíngue. Isso porque, entre os elementos considerados básicos para a consolidação de um Estado, além da unidade étnica e cultural e das fronteiras geográficas, era necessário estabelecer uma unidade linguística. Segundo Ricento (2000), as línguas dos colonizadores foram destinadas a contextos mais especializados, a fim de favorecer o progresso tecnológico, enquanto as línguas locais foram relegadas a outros usos, contribuindo para "perpetuar a estratificação baseada em classes sociais da era colonial” (RICENTO, 2007, p. 13).

Somente nos anos 70, as decisões tomadas por esses primeiros pesquisadores começaram a ser questionadas e seus pressupostos teóricos e metodológicos, problematizados. Conforme Ricento (2000), os estudiosos desse período voltaram a atenção para possíveis efeitos políticos, econômicos e sociais dos contatos linguísticos. Percebeu-se que o planejamento de status empreendido nos anos 50 não contribuiu para o desenvolvimento das comunidades, muito menos para a resolução de conflitos. Nas palavras do autor,

[...] inequidades históricas e conflitos não diminuíram com a seleção de uma língua indígena para uma variedade com funções menos prestigiosas e a designação das línguas europeias para funções especializadas tendeu a perpetuar assimetrias socioeconômicas baseadas na educação, acesso ao que era socialmente controlado por grupos dominantes [...] (RICENTO, 2000, p. 202).

Assim, foram questionadas não apenas as decisões tomadas pelos linguistas em si, mas a própria noção de neutralidade científica foi colocada em xeque, já que a ciência, nesse caso, contribuiu para a legitimação das desigualdades socioeconômicas das comunidades descolonizadas. Nessa perspectiva, as decisões sobre a língua nunca estão desvinculadas de crenças e propósitos macrossociais; as políticas linguísticas são marcadamente ideológicas.

A terceira fase dos estudos do campo, chamada de nova ordem mundial, pósmodernismo, direitos linguísticos humanos, integra as contribuições do período anterior às novas configurações macrossociais, como as alterações provocadas pela queda da União Soviética e a globalização. Recebem atenção nesse momento os estudos sobre perda linguística e valorização das minorias linguísticas, sendo a cura para esse extermínio linguístico uma "responsabilidade política e moral proativa, especialmente a promoção - e aceitação - dos direitos linguísticos humanos pelos estados e pelos órgãos internacionais como princípios universais" (RICENTO, 2000, p. 204). De acordo com Ricento (2000), a síntese das contribuições da teoria crítica, marcantes na segunda fase, e da ecologia linguística, presentes no terceiro momento, forma um novo paradigma nos estudos de política linguística, em que há promoção do multilinguismo e dos direitos humanos linguísticos para os falantes de todas as línguas. 


\section{Perspectiva ampliada}

Fugindo de alguns pressupostos clássicos dos estudos em Política Linguística, como a centralidade da noção de agência, alguns autores começaram a delinear uma nova epistemologia para o campo. Spolsky (2004), em seu livro intitulado Language Policy, argumenta que, para se compreender a política linguística de uma comunidade, é necessário atentar para as práticas localizadas de uso da linguagem, pois normalmente as legislações divergem da prática. Segundo ele, os três componentes que compõem uma determinada política linguística (práticas linguísticas, crenças ou ideologias e o planejamento em si) devem ser considerados.

Partindo dessa concepção, Shohamy (2006) propõe uma visão ampliada da política linguística. Segundo a autora, os documentos e as leis a respeito da língua pouco dizem sobre as práticas linguísticas e, portanto, sobre a política linguística de facto existente em determinados contextos. A autora afirma que a efetivação das políticas linguísticas se dá por meio de diversos mecanismos, os quais estabelecem uma interseção entre as crenças e ideologias que circulam sobre uma determinada língua e as políticas linguísticas de facto. Esses mecanismos incluem as leis e regulamentações linguísticas propriamente ditas, as políticas educacionais, o uso da linguagem nos espaços públicos e os exames de língua. Segundo Shohamy (2006), ao mesmo tempo em que esses mecanismos criam políticas, eles as manifestam.

Ademais, conforme Shohamy (2006), os mecanismos normalmente passam despercebidos pela maior parte da população, o que reforça seu poder, já que eles são concebidos como neutros e inofensivos. A autora despreza esse pressuposto e afirma que, tal como a língua, os mecanismos também são ideologicamente marcados e, portanto, refletem interesses de grupos específicos, estão associados a questões identitárias e auxiliam na manutenção de posições socialmente assimétricas. Além de construírem determinadas crenças sobre a língua e as práticas linguísticas, os mecanismos são responsáveis inclusive por interferir na imposição de comportamentos linguísticos.

Assim, a concepção ampliada de política linguística é bastante produtiva para pensarmos o contexto de sala de aula. Dada a capacidade dos testes de atuarem como mecanismos de criação, manutenção e perpetuação de política linguística, por meio da investigação desses mecanismos e de seus efeitos, é possível compreender o que está em jogo no que diz respeito às políticas linguísticas para uma determinada língua (o que se entende por língua, o que se inclui e se exclui), à formação discente (quais conhecimentos são válidos, quais não são, quais são esperados, quais não) e, claro, à formação docente (responsável por gerenciar todas essas variáveis).

Nesse sentido, para compreender em que medida os testes (enquanto mecanismos de política linguística) conseguem permear o ambiente escolar, é imperativo compreender o chamado "efeito retroativo". Esse fenômeno é intensificado quando se trata de exames de alta relevância, ou seja, exames a partir dos quais se tomam decisões importantes (como, por exemplo, definir a continuação dos estudos no ensino superior).

Nesse artigo, adotamos a definição de Quevedo-Camargo (2004, p. 80) sobre efeito retroativo e utilizamos o termo "para fazer referência ao impacto, à influência, ou às consequências advindas da presença, ostensiva ou não, de algum tipo de instrumento que configure alguma situação de avaliação". Também concordamos com a concepção de Scaramucci $(2005$, p. 39), que define o efeito retroativo como "o impacto ou a 
influência que exames externos e avaliações têm exercido na sociedade em geral e especificamente no ensino e na aprendizagem, assim como nas percepções e atitudes de professores, alunos e formas de preparação". De acordo com as mesmas autoras, após mais de 20 anos de pesquisas sobre o tema, não há dúvidas quanto à existência e complexidade desse fenômeno.

Há uma série de conclusões sobre o tema, propostas no artigo seminal de Alderson e Wall (1993), e sintetizadas da seguinte forma por Scaramucci (2005, p. 42):

a) um mesmo exame pode não ter efeitos, ou ter efeitos parciais ou totais em contextos e participantes distintos; b) o conteúdo do exame, da mesma forma que outros aspectos mais explícitos ou salientes, tais como a natureza dos textos e o método de se avaliar [...] geralmente têm um efeito mais intenso do que sua abordagem e metodologia [...]; c) o efeito pode ser geral, na medida em que leva as pessoas a estudarem mais, independentemente de ser na direção dos conteúdos do exame; e específico, quando leva em conta o conteúdo do teste ou um aspecto específico desse conteúdo; d) o efeito pode ser forte ou fraco, dependendo da intensidade com que se manifesta na sala de aula. É forte quando determina praticamente todas as atividades ou de maneira igual afeta todos os participantes; é fraco quando afeta parte da aula e alguns alunos e professores, mostrando a força de outros elementos; e) o efeito pode durar um período longo ou curto de tempo. [...]; f) o efeito pode ser intencional e não intencional: as consequências sociais intencionais e também as não intencionais de um exame são vistas como efeito retroativo (Messick, 1989; McNamara, 1998); g) pode ser positivo e negativo, sendo também essa última dimensão relacionada com intencionalidade - efeito retroativo positivo tem sido associado com efeito intencional e desejado quando o exame é implementado; efeito retroativo negativo (e positivo) com não intencional, geralmente associado a macetes para se fazer a prova. [...] h) inovações educacionais não são conseguidas, apenas e automaticamente, através da implementação de propostas direcionadas e exames externos.

A autora salienta que os exames de entrada ou acesso, categoria na qual os vestibulares brasileiros se encaixam, ainda que apresentem conteúdos e configurações muito semelhantes, revelam concepções teóricas distintas, as quais precisam ser observadas. Scaramucci (2005) aborda especificamente as mudanças ocorridas no vestibular da UNICAMP e discute os impactos gerados por essas mudanças no contexto educacional de Campinas. Com base nos resultados de oficinas oferecidas pela universidade, Scaramucci (2005) afirma que, enquanto muitos professores procuraram expandir seus conhecimentos teóricos sobre os pressupostos da prova (e, como consequência, ampliaram e melhoraram as práticas de ensino da escrita em sala de aula), em outros contextos, estratégias começaram a ser desenvolvidas para que os alunos se saíssem bem no exame, sem necessariamente tornarem-se leitores e autores.

Para Scaramucci (2005), esperar que todas as consequências envolvidas nos testes sejam controláveis é ingenuidade. Mesmo em casos de exames inovadores como o da UNICAMP, as consequências positivas esbarram na "compreensão de aspectos mais implícitos das propostas, aqueles relacionados principalmente à concepção de linguagem, de escrita e de leitura que fundamentam uma prova como a da UNICAMP" (SCARAMUCCI, 2005, p. 54), devido às crenças e à falta de formação dos professores. Portanto, na concepção da autora, mais interessante seriam propostas de formação que permitissem ao professor realizar a própria prática a partir da compreensão e explicitação das concepções subjacentes aos exames. 


\section{Análise dos dados}

A seguir, apresentaremos as respostas dos professores às questões propostas no questionário online, aplicado ao final do primeiro semestre de 2016, e apontaremos aspectos relevantes para a análise aqui proposta, a saber, o impacto dos vestibulares e ENEM nas práticas docentes. As sete primeiras questões, a respeito do perfil pessoal e profissional dos respondentes, já foram apresentadas na introdução deste trabalho. Aqui, apresentaremos as outras nove, diretamente relacionadas ao objetivo da investigação proposta. Alguns trechos foram colocados em negrito para destacar aspectos interessantes das declarações.

A primeira pergunta aqui apresentada trata do contexto de atuação do professor. Quando perguntados se seus alunos/alunas fariam ENEM ou vestibulares em 2016, 25\% dos professores respondeu que todos fariam; $58,3 \%$ que a grande maioria faria; $8,3 \%$ que a grande maioria não faria e, por fim, outros $8,3 \%$ responderam que ninguém faria. Saber essa informação é crucial, já que, caso a resposta seja negativa, há uma tendência de impacto menor ou nulo dos vestibulares na prática docente.

Apesar de nem todos os professores lecionarem exclusivamente para alunos que fariam ENEM ou vestibulares, $100 \%$ dos entrevistados respondeu que reservam algum momento das aulas para abordar os exames. Em outras palavras, mesmo em contextos em que aparentemente o vestibular não apresenta nenhuma relevância para os alunos em questão, dado que eles não passarão por esse momento de avaliação, os professores abordam esse tipo de exame em sala de aula. Essas respostas sugerem que o impacto dessas avaliações é muito mais amplo do que se supõe à primeira vista.

Em seguida, em relação à quantidade de tempo destinada para esse tópico, as respostas foram bastante díspares. Há quem afirme utilizar $50 \%$ do tempo semanal de aula, 15-20 minutos, 10 ou 5 minutos em todas as aulas ou duas vezes por bimestre. Contudo, é importante destacar que $27 \%$ dos professores relatou que usava todo o tempo da aula com os vestibulares. Um dos respondentes escreveu que utiliza

(1) "A aula toda, pois as aulas são realizadas especificamente para abordar o gênero textual dos vestibulares, entre eles o ENEM.".

Assim, é possível perceber que, para alguns professores em algumas escolas, os vestibulares são os principais norteadores das aulas de língua portuguesa. Quando não são, esses exames ainda têm espaço entre as atividades desenvolvidas em sala. A resposta (1) indica que, em alguns espaços, há uma restrição das atividades escolares, que se tornam exclusivamente dependentes do que há nos exames. No caso específico do ENEM, por exemplo, quando este se torna o principal foco, há uma restrição na abordagem da produção textual, uma vez que o exame exige a produção de um texto dissertativoargumentativo, o qual foge da concepção de ensino voltada para gêneros diversos, pautada numa concepção social de uso da leitura e da escrita.

Em seguida, perguntado o porquê de abordarem (ou não) os vestibulares em sala, as respostas foram também significativas.

(2) "O ENEM tem sido instrumento de avaliação para a entrada em universidades no país e fora dele. Portanto, os alunos que pretendem ingressar no ensino superior precisam entender as questões e a configuração do exame.".

Esse respondente reconhece o papel do ENEM não como um instrumento para a avaliação do Ensino Médio do país - função primeira do exame -, mas como um 
mecanismo de entrada no Ensino Superior, dada a sua abrangência e número de vagas disponíveis via Sistema Único de Seleção (SISU). Além disso, o respondente acredita que, por ser um exame importante, os alunos precisam estar já habituados a ele, ou melhor, estarem treinados para realizar o teste. Em contrapartida, os alunos que não pretendem entrar no ensino superior não se encaixariam nesse tipo de aula. O ensino seria, portanto, determinado a promover subsídios para a aprovação no vestibular. Essa ideia de treinamento para um teste como objetivo do trabalho em sala de aula aparece em outras respostas, demonstrando o que Shohamy (1993) já apontava há anos sobre o efeito das provas no ensino: transformação das aulas em treinamento para o teste, o que obscurece o currículo escolar existente.

Outra razão apontada para abordar os vestibulares é a pressão institucional. A necessidade de se abordar os exames em sala de aula às vezes é uma exigência da escola, que posiciona o treinamento para os exames como uma estratégia de marketing para um produto desejável. Nesse sentido, as duas respostas a seguir são emblemáticas:

\footnotetext{
"Porque as instituições que eu trabalho preparam para o vestibular.".
}

"Porque, contrário ao meu entendimento de ensino, o foco final do EM é a aprovação no vestibular.".

A resposta (3) vai direto ao ponto e afirma abordar os exames em sala de aula por trabalhar em uma instituição que tem esse viés como pressuposto. Há indícios nessa resposta de que não se trata de uma escolha propriamente dita, mas de uma adequação às exigências institucionais. É possível imaginar que, em outro contexto de atuação, esse respondente não agisse da mesma forma.

A resposta (4), por sua vez, apresenta uma discordância do aparente consenso de que os anos finais do Ensino Médio devem preparar o aluno para a aprovação no vestibular. Nesse sentido, a atitude resignada do respondente se dá por uma ideia que circula socialmente, mas também no contexto educacional, de que o destino final do ensino médio é o vestibular. Contudo, de acordo com as Orientações Curriculares para o Ensino Médio (2006, p. 7), tal etapa de ensino tem como finalidades "o aprimoramento do educando como ser humano, sua formação ética, desenvolvimento de sua autonomia intelectual e de seu pensamento crítico, sua preparação para o mundo do trabalho e o desenvolvimento de competências para continuar seu aprendizado.". Com base nesses objetivos, compreende-se que a preparação para os exames vestibulares, etapa necessária para a continuidade dos estudos no ensino superior, seria apenas uma das funções dessa etapa de ensino. Assim, não há problema em se abordar aspectos relacionados a esses exames; o problema estaria em restringir o ensino a um treinamento específico para a prova $\mathrm{x}$ ou $\mathrm{y}$. analisada:

Por fim, ainda em relação a essa questão, a resposta (5) também merece ser

"Porque se trata de um exame importante que não só visa ao ingresso na Universidade, como também prepara o aluno para escrever melhor, ler, interpretar, selecionar informações e outras habilidades e competências.".

O respondente (5) atribui ao exame a capacidade de preparar o aluno para desenvolver habilidades desejáveis e apontadas como requisitos ao final do ensino médio. Assim, não seria o trabalho do professor e as horas de estudos individuais as responsáveis por um aluno que "escreve melhor", lê, interpreta e seleciona informações, mas a 
existência de um teste. Nesse sentido, é atribuída aos exames a capacidade de formar alunos melhores do que seriam formados caso não existissem exames. Essa é normalmente uma das justificativas para se incluir esse tipo de avaliação ao final de etapas, pois, segundo Shohamy (1993), em países cujo sistema educacional é centralizado, existe a crença de que, por meio de testes, é possível manipular comportamentos. Mais do que isso, acredita-se que há importância apenas nos conteúdos, habilidades e competências exigidas nos exames; o que fica de fora dos testes não deve ser objeto de ensino ou aprendizagem.

Apesar de todos os respondentes afirmarem que abordam os exames em suas aulas, nem todos consideram que estes exercem influência em sua prática diária em relação ao conteúdo. $82 \%$, por outro lado, acreditam que os conteúdos dos exames são atuantes nesse aspecto. Perguntados sobre a dimensão dessa influência (quanto/em que aspectos ocorria), a maioria revela que os exames são determinantes para definir o currículo do Ensino Médio:

(6) "Norteiam o trabalho.".

(7) “Guiam a preparação e condução das aulas.".

(8) "Direcionamento da aula e do conteúdo para atender aos critérios exigidos pelos processos seletivos.”.

As respostas (6), (7) e (8) são abrangentes, mas são relevantes para a compreensão de como o trabalho docente é impactado por esses exames. As três palavras iniciais das respostam têm um sentido parecido, de orientar a prática docente, estabelecer os caminhos a serem percorridos ao longo do ano para que, ao final, o objetivo maior - a aprovação seja alcançado. Nesse sentido, se os exames têm a função de nortear a prática, de dar direcionamento, guiar as ações dos professores, essas avaliações assumem uma importância não apenas na vida dos alunos, conforme apresentado nas respostas às primeiras questões, mas também para o professor do Ensino Médio, posto que, a partir dessas respostas, é notável a autoridade presente nesse processo avaliativo, tanto que este ocupa status semelhante - ou mesmo superior - a documentos exclusivamente elaborados para nortear e fornecer subsídios para a prática docente.

A resposta (9) retoma a ideia de treinamento para o teste e especifica que as questões relevantes a serem abordadas em sala de aula seriam aquelas passíveis de aparecerem nos exames:

(9) "Acredito que interfere $80 \%$ na minha prática, pois busco refletir e elaborar as atividades sobre os temas atuais e interessantes que podem ser abordados na prova, trazendo também questões no formato do exame para que os estudantes se acostumem com o estilo da prova.".

Assim, uma questão social ou um tema qualquer será objeto de discussão em sala caso este também seja uma possibilidade para o exame. Nesse ínterim, corre-se o risco de generalização dos conteúdos, pois as realidades locais podem estar à mercê de temáticas abstratas e pouco significativas para os alunos.

Outra questão abordada pelos respondentes coloca os exames vestibulares como uma espécie de formação continuada para professores. Como é possível perceber a partir da resposta (10), a atualização constante do professor é uma das formas de interferência possível desses mecanismos de avaliação: 
(10) "Em relação às notícias do Brasil e do mundo, pois é preciso estar em contato com isso para trabalhar alguns assuntos que possivelmente podem ser tema de questões e da própria redação do ENEM. Além disso, a cada pequena mudança realizada na prova o professor deve estar atento, pois às vezes é preciso alterar a forma em que se trata o gênero dissertativo-argumentativo para estar de acordo com o exame, ou seja, é preciso estar em constante aprendizado para compartilhá-lo com os estudantes.".

$\mathrm{Na}$ questão seguinte, os respondentes foram convidados a avaliar a interferência promovida por esses exames. Para $67 \%$ deles, a influência promovida em suas práticas docentes diárias pelos exames é positiva; para 33\%, é parcialmente positiva. As justificativas foram similares: os que as consideram positiva atribuem-na à constante atualização necessária para que o professor consiga abordar os exames em sala. $\mathrm{O}$ benefício aqui estaria na promoção de uma aprendizagem docente continuada, possível devido às exigências dos exames. Os que a consideram parcialmente positiva dizem que os exames são limitadores da criatividade e que conteúdos considerados interessantes acabam sendo obliterados.

Em seguida, a penúltima questão feita aos respondentes foi a seguinte: "se há divergência entre conteúdos dos exames vestibulares e o que se propõe em documentos oficiais de ensino, você prefere escolher quais das opções para seguir? Por quê?". Nesse quesito, a maioria dos professores opta pelos conteúdos dos vestibulares. Outra parte tenta assumir uma postura conciliadora e apenas um dos respondentes afirma preferir os documentos oficiais de ensino.

(11) Vestibular é o que importa aos meus alunos

(12) Trabalho de acordo com a política das escolas, preparo para o vestibular.

(13) Prefiro seguir os conteúdos dos exames vestibulares, pois se ensinarmos o que está nos documentos oficiais os alunos não vão conseguir realizar as provas, por não saber o conteúdo e as informações estarem divergentes entre o que é ensinado e o que está na prova.

A resposta (12) é bastante pragmática e revela a falta de liberdade que muitos professores vivenciam, especialmente em instituições particulares. Nessa resposta, novamente, não se atribui a opção de se basear em x ou y a uma decisão individual, firmada em crenças pessoais, mas pautadas exclusivamente na postura da instituição em priorizar determinados conteúdos em detrimento de outros. Nesse sentido, é relevante pensar nas políticas linguísticas também a partir do ponto de vista das administrações escolares, dado o seu papel muitas vezes determinante na condução do trabalho docente. Merece destaque também a resposta (13), a qual reconhece a distância muitas vezes existente entre os conteúdos propostos pelos documentos oficiais de ensino e os cobrados no vestibular. Nesse sentido, somente com um treinamento voltado para o exame, é possível garantir o sucesso dos alunos.

A resposta (14) destoa das demais, por propor outra visão a respeito do que se espera do ensino médio, da formação dos alunos e também do trabalho docente:

(14) Busco seguir as propostas dos documentos oficiais de ensino, pois buscamos a formação de um aluno crítico e participativo, não devemos apenas treiná-lo para exames vestibulares. Contudo, na minha opinião, é importante os professores demonstrarem os caminhos para que os estudantes tenham a possibilidade de estudar questões específicas desses testes, mas esse não deve ser o foco. 
Assim, na visão desse professor, um aluno bem formado seria aquele capaz de ser crítico e participativo, não treinado para a realização de uma prova. Seguindo esse raciocínio, o bom professor seria aquele capaz de desenvolver essas habilidades, não técnicas para ter um bom desempenho. Além disso, ao sugerir a escolha pelos documentos oficiais dada a necessidade de formar determinados tipos de aluno, o professor em questão também sugere que esse aluno não pode ser formado com o modelo de exame existente até o momento. É interessante notar portanto que, em se tratando de avaliação, questões de identidade tornam-se salientes.

Por fim, em relação ao último item do questionário (como a instituição em que você trabalha se posiciona em relação aos conteúdos dos exames vestibulares?), nem todos os participantes o responderam. Em geral, os respondentes confirmaram o que já havia sido expresso nas perguntas anteriores, conforme os exemplos a seguir, ainda que para justificar respostas dadas a outros recortes:

(15) Criteriosa, rígida e exigente para contemplá-los integralmente.

(16) É o principal foco.

(18) Valida os conteúdos.

A resposta (19), contudo, apresenta uma posição diferente sobre a questão:

(19) A instituição demonstra que é importante trabalhar os principais conteúdos cobrados nos exames vestibulares, mas o professor deve saber adequá-los ao seu planejamento de forma consciente e significativa, fazendo com que o aluno reflita sobre o que está sendo estudado e não apenas decorando a matéria.

Assim, é possível perceber que, para esse participante, ainda que a instituição enfatize a abordagem dos conteúdos dos vestibulares, o professor deve ser autônomo e atuar de forma a tornar esses conteúdos mais significativos. Há um pressuposto implícito a essa resposta de que conteúdos de vestibulares não seriam significativos, mas apenas "decoreba", informações úteis exclusivamente para a realização das provas, sem a necessidade de reflexão, apenas repetição. Assim, também subjaz a essa resposta a preocupação com o tipo de aluno que está sendo formado: um aluno crítico e reflexivo ou um aluno copista e mero reprodutor de conteúdos? Essas diferenças conceituais, relacionadas à identidade de estudante, também são levantadas a partir de uma reflexão sobre os exames. Tais questões são fundamentais para todas as áreas do conhecimento, não apenas para o ensino de língua portuguesa, mas são especialmente eloquentes ao revelarem os verdadeiros pressupostos ou, nas palavras de Shohamy (2006), as políticas linguísticas de facto estão em vigor em uma determinada comunidade.

\section{Considerações finais}

Ao final das discussões aqui propostas, que tiveram como objetivo analisar os impactos promovidos pelos exames vestibulares na prática docente de professores da região de Curitiba, é evidente o quanto de pesquisa ainda é necessário para que todas as variáveis em jogo sejam compreendidas e avaliadas. Dentro das limitações de alcance deste trabalho e de espaço para relatar os resultados, algumas considerações são necessárias.

Como já era esperado, dado o volume de pesquisas sobre o tema, os vestibulares provocam impactos diversos na prática docente. A seleção de conteúdos, a definição do 
currículo e o desenvolvimento de materiais estão marcados pela presença dessas provas, como instrumentos que norteiam a organização das aulas. Além disso, a pressão institucional também é marcante, já que muitas das escolas em que os professores entrevistados atuam consideram essas avaliações indispensáveis e, portanto, estas devem ser objeto de aprendizagem. Somados, tais aspectos criam uma aparente normalização do que se espera de uma sala de aula ao longo do ensino médio: um treinamento para o vestibular. A redução do currículo ao que se espera de provas externas, baseada em concepções de língua, ensino, sujeito e educação pouco discutida com os professores em geral, sugere uma perspectiva também de redução da prática docente - múltipla e dependente do contexto em que se insere - a uma reprodução de técnicas e fórmulas para um bom desempenho nos exames.

Por outro lado, apesar dessa aparente restrição da atuação docente, presa aos conteúdos dos vestibulares, as respostas dos professores indicaram que a maioria considera positiva a interferência dessas provas em seu cotidiano profissional, por promover o constante aprimoramento e atualização de suas práticas. Assim, ouvir os professores permitiu uma outra leitura dessa questão e reafirmou a complexidade do efeito retroativo, já que a valoração depende da perspectiva do observador.

Nesse sentido, considerando os impactos promovidos pelos vestibulares (por um lado, uma série de restrições ao ensino e à prática docente e, por outro, possíveis ganhos para a formação dos professores), promover um diálogo maior entre a esfera acadêmica e os profissionais que atuam nas escolas é imperativo. Estudos como os de Shohamy (1993, 2006), os quais abordam as implicações dos testes, seja por vê-los como mecanismos de políticas linguísticas, seja por estudar o efeito retroativo destes na escola, são fundamentais para uma concepção mais ampla sobre o que está em jogo quando se propõem avaliações, especialmente as de larga escala, como o ENEM.

Ampliar o repertório dos professores sobre avaliação pode modificar as opiniões positivas deles sobre os impactos que elas exercem no contexto escolar. Afinal, estar atualizado quanto a discussões sociais (impacto positivo apontado por respondentes) é um tanto genérico e despreza muitos pressupostos teóricos e metodológicos presentes nesses exames. O quanto, de fato, esses professores conhecem os exames que os impactam é uma questão a ser colocada. A responsabilidade da academia também reside nesse aspecto. A formação continuada do professor precisa responder à prática, às necessidades de sua atuação. Assim, num contexto em que as instituições de ensino esperam do professor uma postura de treinador, é preciso construir pontes: quais são as implicações dessa postura? Que pressupostos estão em jogo quando se opta por determinados conteúdos em detrimento de outros? Como o professor pode se colocar de maneira informada nesse processo? Como ele pode conciliar demandas? As respostas a essas perguntas exigem um trabalho conjunto, em que a universidade retome seu papel de formação, a fim de problematizar o que a prática docente naturalizou. É preciso também que a escola coloque a universidade em xeque, por tantas vezes ignorar o que se passa nas salas de aulas e não conseguir formar professores capazes de gerenciar tantas demandas dissonantes.

Se, como colocou Quevedo-Camargo (2014), há poucos estudos sobre os impactos positivos dos testes, talvez isso seja fruto de um olhar viciado, atento a buscar os problemas, mas pouco assertivo em relação a promover mudanças significativas. Talvez as perguntas feitas estejam erradas. 


\section{REFERÊNCIAS}

ALDERSON, J. C.; WALL, D. Does washback exist? Apllied Linguistics, 14, p. 115-129, 1993.

BAKHTIN, M. Teoria do romance I: a estilística. São Paulo: Editora 34, 2015.

BRASIL/MEC/SEB. Orientações curriculares para o ensino médio: Linguagens, códigos e suas tecnologias. Brasília: MEC/SEB, 2006. Disponível em: $<$ http://portal.mec.gov.br/seb/arquivos/pdf/book_volume_01_internet.pdf $>$. Acesso em: 10 ago. 2016.

QUEVEDO-CAMARGO, G. Efeito Retroativo da avaliação na aprendizagem de línguas estrangeiras: que fenômeno é esse? In: MULIK, K. B.; RETORTA, M. S. Avaliação no Ensino-Aprendizagem de Línguas Estrangeiras: Diálogos, Pesquisas e Reflexões. Campinas: Pontes Editores, 2014. p. 77-93.

RICENTO, T. Historical and theoretical perspectives in language policy and planning. Journal of Sociolinguistics 4/2, p. 196-213, 2000.

. Language Policy: Theory and Practice - An introduction. In: RICENTO, T. An introduction to language policy: theory and method. Blackwell Publishing, 2007.

SCARAMUCCI, M. V. R. Prova de redação nos vestibulares: educacionalmente benéfica para o ensino/aprendizagem da escrita? In: FLORES, V. do N.; NAUJORKS, J. da C.; REBELLO, L. S.; SILVA, D. S. (Org.). A Redação no Contexto do Vestibular 2005 - A avaliação em perspectiva. Porto Alegre: Editora da UFPRGS, 2005. p. 37-57.

Validade e consequências sociais das avaliações em contextos de ensino de línguas. L I N GVARVMARE NA, v. 2, p. 103-120, 2011.

SHOHAMY, E. The Power of Tests: The Impact of Language Tests on Teaching and Learning. NFLC Occasional Papers, June, 1993

Language Policy: Hidden agendas and new approaches. Routledge, 2006.

SPOLSKY, B. Language Policy - Key topics in Sociolinguistics. Cambridge University Press, 2004.

TARDIF, M. Saberes docentes e formação profissional. 4. ed. Rio de Janeiro: Vozes, 2014.

Recebido em: 16/08/2016

Aprovado em: 06/02/2017 


\section{ANEXOS}

\section{Pesquisa sobre a interferência dos vestibulares e Enem na prática docente}

1. Idade:

2. Cidade - Estado:

3. GRADUADO: em que ano você concluiu o curso?

4. GRADUANDOS: qual período está cursando?

5. Atua como professor há quanto tempo?

6. Local de atuação:

( ) Instituição Pública

( ) Instituição Privada

( ) Autônomo

( ) Outros

7. Ministra aulas para alunos do Ensino Médio atualmente?

( ) Sim ( ) Não

8. Seus alunos/alunas farão ENEM ou vestibular esse ano?

( ) Sim, todos farão.

( ) Sim, a grande maioria fará.

( ) Não, a maioria não fará.

( ) Não, ninguém fará.

9. Você reserva algum momento da sua aula para falar especificamente desses exames?

( ) $\operatorname{Sim}$ ( ) Não

10. Se sim, quanto tempo aproximadamente?

11. Por que você faz essa escolha enquanto profissional?

12. Os conteúdos desses exames interferem na sua prática docente diária?

13. Se sim, quanto? Em que aspectos?

14. Como você avalia essas interferências? Explique.

15. Se há divergência entre conteúdos dos exames vestibulares e o que se propõe em documentos oficiais de ensino, você prefere escolher quais das opções para seguir? Por quê?

16. Como a instituição em que você trabalha se posiciona em relação aos conteúdos dos exames vestibulares? 